\title{
EVOLUTIONARY GAME ANALYSIS BETWEEN IMMIGRATION AND DEVELOPERS: A CASE STUDY OF HYDROPOWER DEVELOPMENT PROJECT
}

\author{
ZENG SHENG \& JIN JINGYU \\ School of Finance and Fiscal Affairs, Chongqing Technology and Business University, \\ People's Republic of China.
}

\begin{abstract}
Hydropower is a clean renewable energy because of rich water resources and great potential for its development in our country. Game payoff matrix between immigration and developers of hydropower development project shows that the best stable points or strategies is the dual high cost between immigration and developers of hydropower development project, which makes sure the success of hydropower development project. Our suggestion is improving immigrants' compensation system to achieve the harmonious development between hydropower development project and society, broadening the financing channels of hydropower development project, strengthening the government support and management of hydropower development, and promoting the orderly development of hydropower projects.

Keywords: developers, evolutionary game, hydropower development, immigration.
\end{abstract}

\section{INTRODUCTION}

Energy is a necessity for the development of society and economy. So far, it is increasingly evident that our country is short of energy. In 2011, the total energy production in our country was 317,987 tons of standard coal, the total energy consumption was 348,002 tons of standard coal, and the supply shortfall reached 30,015 tons of standard coal. It indicated that the shortage of energy will restrict the development of society and economy in the future. (Data resource: China Statistical Yearbook, 2012). At the same time, the energy consumption will be affected by the target of the carbon emission. It can ease the contradiction between energy supply and demand to develop hydropower vigorously, and it also conforms to the requirements that the energy consumption should reduce the carbon emission and the sustainable development [1-3]. However, to implement hydropower development successfully, immigration that caused by hydropower development will be involved. There is a game relationship between developer of hydropower development project and immigration. Too low compensation will cause the immigration's unwillingness to move, which will hinder the implementation of hydropower, whereas too high compensation required by immigration will lead to high cost of the hydropower development, which will hinder the advance of the project also. It is of great significance for hydropower to seek a stable and harmonious relationship between developer of hydropower development project and immigration.

There is less existing literature at home and abroad about evolutionary game analysis between immigration and developers of hydropower development in the hydropower development project. Shi Zuliu and Sun Jinhua analyzed the relationship among the central government, local government and owners in the hydropower development project and immigration management [4]. Fan Hui and Liu Yufeng qualitatively analyzed the game between local interests and the interests of developers of the hydropower development in a period of rapid between hydropower development project [5]. Su Qian applied Game Theory to analyze the relation of stakeholders including hydropower development company, immigration, 
local government, environmental protection volunteers, etc. in the hydropower projects [6]. Zeng Jiansheng applied simple description of the game analysis to analyze the three stakeholders: the local government, the immigration agency and the immigrant in immigration work [7]. Li Qinghua thought that the adjustment of the interests among company, residents, government and non-governmental organizations in the hydropower development project need to apply the corresponding laws and regulation [8]. Yan Dengcai et al. explored the issues between hydropower development and local development of ethnic minority immigrants in GuangXi as example [9]. Liu Jianhua analyzed the correlation between social game and the interests of coordination [10].

By analyzing the literature, the experts and scholars mainly qualitatively analyzed the game relationship among hydropower development (or Hydropower Development Company), government, immigration agency and immigration (or residents), and the 'prisoner dilemma' model is the only game model applied to analyzing them. Based on the existing literature and by the use of evolutionary game model, this paper analyzes the relation between immigration and developers of hydropower development project, pursuing the game between the stable points and realizing the coordinated development in order to achieve the sustainable development of the hydropower development projects.

\section{MODEL DESCRIPTIONS}

In the hydropower development project, according to the interests of the relationship between immigration and developers of hydropower development, this paper for both sides of the game has the following hypothesis:

First, major participants: The developer of hydropower development (development companies or government) who has certain advantage in the game competition is the main party in the game model; The other main participation body is immigrants (or resident). We assumed that participators are bounded rationality.

Secondly, action strategy: In the game model of strategy selection, the immigrants can use tactics schemes: voluntary resettlement or involuntary resettlement. And the developer of hydropower development can use tactics schemes: successful development or unsuccessful development. (The reason for unsuccessful development is not to give up project, which is the main reason for the development producing some serious negative impact, such as environmental damage or social impact.)

Thirdly, information acquisition: In the model, participants cannot accurately predict the strategy of the other party, namely incomplete information that the information is need cost.

Fourthly, income set: The developers would have profit $(R)$ from the successful development of hydropower project, and relocation costs is $c$ in the project, and the compensation of immigrant is $P$ (This standard is following the regulations of the state policy, at the same time, the developers pay the cost of relocation.), meanwhile $P>c$, in which the compensation of immigrants should be higher than the costs of relocation. Besides relocation and settlement, the compensation should include future survival and development funds.

The developers would have profit $\left(R_{s}\right)$ from the successful development of hydropower project, or the profit of unsuccessful project is $R_{f}$ (for example, from the government's compensation or social benefits), and loss or cost is $c_{2}$. Under involuntary resettlement, the compensation of immigrants is $P$; meanwhile, it is the cost that the developers pay to the compensation of relocation to guarantee smooth implementation. Under the situation of unsuccessful development, the immigrants also can obtain income or recoup their losses $(Q)$, which come from the compensation of unreasonable hydroelectric development. The relocation cost is $c$, but if the immigrants have involuntary resettlement, the income is the saving 
Table 1: Income matrix of game payoff between immigrants and developers of hydropower.

\begin{tabular}{lccc}
\hline & \multicolumn{2}{c}{ Immigrant } \\
\cline { 3 - 4 } Developer & $\begin{array}{c}\text { Successful } \\
\text { development } \\
\text { Unsuccessful } \\
\text { development }\end{array}$ & $R_{s}-P, P$ & $R_{s}-P, c$ \\
\hline
\end{tabular}

cost $(c)$. Assuming the probability whether hydropower development project can be completed is $f$. Under the situation of successful development, the hydroelectric developers must pay for $R_{s}-P$, or they should pay for $R_{f}-f^{*} c_{2}-Q$ and $R_{f}-f^{*} c_{2}$. At the same time, under the situation of voluntary resettlement, the immigrants will obtain income $(P$ and $Q)$, or the income is $c$ and $c-f^{*} c_{1}$. Considering this situation, this paper builds the game payoff matrix as shown in Table 1 [11,12].

\section{MODEL ANALYSIS}

Next, this paper separately tests fitness and stability of the model.

\subsection{Fitness of the game model}

Table 1 illustrates the income and payoff matrix of the game between immigrants and developers of hydropower, who can analyze the fitness of the model. Now, we assume that the probability of voluntary resettlement is $y$, and the probability of involuntary resettlement is (1 $-y$ ) in the development hydropower project. Similarly, the probability of successful development is $x$,or it is $(1-x)$.

When the hydropower developers successfully fulfill the project, the fitness can be written as

$$
u_{1}=y\left(R_{s}-P\right)+(1-y)\left(R_{s}-P\right)=R_{s}-P
$$

When the hydropower developers do not fulfill the project, the fitness can be written as

$$
u_{2}=y\left(R_{f}-f * c_{2}-Q\right)+(1-y)\left(R_{f}-f * c_{2}\right)=R_{f}-f * c_{2}-y Q
$$

The fitness of hydropower developer expectations can be written as

$$
\begin{aligned}
\bar{u}= & x\left(R_{s}-P\right)+(1-x)\left(R_{f}-f * c_{2}-y Q\right)=\left(R_{f}-f * c_{2}-y Q\right)+ \\
& x\left(R_{s}-R_{f}+y Q+f * c_{2}-P\right)
\end{aligned}
$$

Therefore, when the hydropower developers successfully fulfill the project, the replicated dynamic equation can be written as the following equation:

$$
\begin{aligned}
u_{t}^{\prime} & =x\left(u_{1}-\bar{u}\right)=x\left\{\left(R_{s}-P\right)-\left[\left(R_{f}-f * c_{2}-y Q\right)+x\left(R_{s}-R_{f}+y Q+f * c_{2}-P\right)\right]\right\} \\
& =x(1+x)\left(R_{s}-R_{f}+f * c_{2}+y Q-P\right)
\end{aligned}
$$


Similarly, when the immigrants choose voluntary resettlement, the fitness can be written as follows:

$$
v_{1}=x P+(1-x) Q
$$

Meanwhile, when the immigrants choose involuntary resettlement, the fitness can be written as in eqn (6):

$$
v_{2}=x c+(1-x)\left(c-f * c_{1}\right)=c-(1-x) f^{*} c_{1}
$$

The fitness of immigrant expectations can be written as

$$
\bar{v}=y[x P+(1-x) Q]+(1-y)\left[c-(1-x) f * c_{1}\right]
$$

Thus, when the immigrants choose voluntary resettlement, the replicated dynamic equation can be written in the following:

$$
v_{t}^{\prime}=y\left(v_{1}-\bar{v}\right)=y(1-y)\left(\left(Q+f * c_{1}-c\right)-x\left(Q-P+f * c_{1}\right)\right)
$$

Equations (4) and (8) describe population dynamics of game competition evolution system between the hydroelectric developers and the immigrants in hydropower development project. Therefore, the replicated dynamic equation of this evolution system can be written as

$$
\left\{\begin{array}{l}
u_{t}^{\prime}=x(1+x)\left(R_{s}-R_{f}+f^{*} c_{2}+y Q-P\right) \\
v_{t}^{\prime}=y(1-y)\left[\left(Q+f * c_{1}-c\right)-x\left(Q-P+f * c_{1}\right)\right]
\end{array}\right.
$$

According to Friedman's (1991) method, the stability of the equilibrium point can be reached by analyzing the Jacobi determinant of game competition system. The Jacobi determinant is given as

$$
J=\left|\begin{array}{ll}
(1+2 x)\left(R_{s}-R_{f}+f * c_{2}+y Q-P\right) & x(1+x) Q \\
-y(1-y)\left(Q-P+f * c_{1}\right) & (1-2 y)\left[\left(Q+f * c_{1}-c\right)-x\left(Q-P+f * c_{1}\right)\right]
\end{array}\right|
$$

The determinant of matrix $J$ is

$$
\begin{aligned}
\operatorname{det} J= & {\left[(1+2 x)\left(R_{s}-R_{f}+f * c_{2}+y Q-P\right)\right] *(1-2 y)\left[\left(Q+f * c_{1}-c\right)-x\left(Q-P+f * c_{1}\right)\right] } \\
& +[x(1+x) Q]\left[y(1-y)\left(Q-P+f^{*} c_{1}\right)\right]
\end{aligned}
$$

The trace of matrix $J$ is

$\operatorname{tr} J=\left[(1+2 x)\left(R_{s}-R_{f}+f^{*} c_{2}+y Q-P\right)\right]+(1-2 y)\left[\left(Q+f * c_{1}-c\right)-x\left(Q-P+f^{*} c_{1}\right)\right](12)$

\subsection{Stable point analysis of the game model}

The principle of the above conditions and assumptions is based on the model of the evolutionary stable strategy, namely the action of hydroelectric developers and immigrants is 
rational without collusion or collaboration in the hydropower development project. Actually, both the sides, hydroelectric developers and immigrants, take into account their own benefit maximization. Therefore, excluding collusion or collaboration action, we can analyze the game process between the hydroelectric developers and the immigrants in the hydropower development project, which can reveal the orientation of the rational behavior of both sides and stable points. When the case is that hydroelectric developers and immigrants take into account their own benefit maximization in the hydropower development project, we can generalize four kinds of game situations between developer and immigrant.

3.2.1 The game behavior of the respective high-cost between hydroelectric developers and immigrants

From eqns (9), (10) and (11) obtained, when $P>\left(R_{s}-R_{f}+f^{*} c_{2}+Q\right)$ and $c>\left(Q+f^{*} c_{1}\right)$, the replicated dynamic equation of the game model has four equilibrium points of $(0,0),(1,0)$, $(1,1)$ and $(0,1)$. Table 2 illustrates the value and trace of matrix of equilibrium point.

Table 2 shows that $(0,0)$ and $(1,1)$ represent stability point of the respective high cost of hydroelectric developers and immigrants in the development of hydropower projects. The stability point $(0,0)$ expressing in the project that when the cost of hydropower development project of developers is greater than the sum of the future profits and social impact, the developers would rather choose to give up it. Similarly, when the cost of immigrant resettlement is greater than the compensation, the immigrants would rather choose not to relocate. In this case, the central and local governments' mandatory requirements will lead immigrates to appeal or riot, and obstruct the hydroelectric development project. What's more, it will increase the cost of hydroelectric development project, and at the same time the developers would rather choose to give it up. The stability point $(1,1)$ means that the respective high cost accepted by hydroelectric developers and immigrants impels the process smooth of hydroelectric development project. It is inconsistent with common sense that developers and immigrants accept the respective high cost, but this result probably stems from bounded

Table 2: Stable point analysis of the respective high cost between developers and immigrants.

\begin{tabular}{lcccc}
\hline Equilibrium point & Equation & Symbol & $\begin{array}{c}\text { Local } \\
\text { stability }\end{array}$ \\
\hline$x=0, y=0$ & $\operatorname{det} J$ & $\left(R_{s}-R_{f}+f * c_{2}-P\right)\left(Q+f * c_{1}-c\right)$ & $>0$ & $E S S$ \\
& $\operatorname{tr} J$ & $\left(R_{s}-R_{f}+f * c_{2}-P\right)+\left(Q+f * c_{1}-c\right)$ & $<0$ & \\
$x=1, y=0$ & $\operatorname{det} J$ & $3\left(R_{s}-R_{f}+f * c_{2}-P\right) *(P-c)$ & $<0$ & Saddle \\
& $\operatorname{tr} J$ & $3\left(R_{s}-R_{f}+f * c_{2}-P\right)+(P-c)$ & point \\
$x=1, y=1$ & $\operatorname{det} J$ & $3\left(R_{s}-R_{f}+f * c_{2}+Q-P\right) *(-P+c)$ & $>0$ & $E S S$ \\
$x=0, y=1$ & $\operatorname{tr} J$ & $3\left(R_{s}-R_{f}+f * c_{2}+Q-P\right)+(-P+c)$ & $<0$ & \\
& $\operatorname{det} J$ & $-\left(R_{s}-R_{f}+f * c_{2}+Q-P\right)\left(Q+f * c_{1}-c\right)$ & $<0$ & Saddle \\
& $\operatorname{tr} J$ & $\left(R_{s}-R_{f}+f * c_{2}+Q-P\right)-\left(Q+f * c_{1}-c\right)$ & & point \\
\hline
\end{tabular}


rationality of the two parties. With the rapid development of economy and enhancing of the living standard, it is indisputable truth that the cost of successfully fulfilling the project is high. Simultaneously, in order to obtain better living condition after the relocation, the immigrants are willing to choose the high compensation even the cost of relocation is very high.

3.2.2 The game behavior between low cost of developers and high cost of immigrants in the hydroelectric development project

When $P<\left(R_{s}-R_{f}+f * c_{2}+Q\right)$ and $c>\left(Q+f * c_{1}\right)$, the replicated dynamic equation of Game model has four equilibrium points: $(0,0),(1,0),(1,1)$ and $(0,1)$. Table 3 illustrates the value and trace of matrix of equilibrium point.

Table 3 shows assuming low cost of developers and high cost of immigrants in the hydroelectric development project, the stability point is $(0,1)$, which means even though the developers face low cost, the high cost of relocation probably compels developers to choose to give it up. It is possible in the project that the relocation needs high cost and the immigrants are willing; at the same time, the developers also have low cost. On one hand, the immigrants are willing probably by governments' mandatory requirement; on the other hand, the relocation of high cost will certainly pass on hydroelectric developers. It seems that the developers implement the project with low cost, but they finish it with high cost; at the same time, they also take the risk that the immigrants who are forced to move by the government are likely to require additional compensation and provoke violence. Therefore, the developers are likely to give up the project.

3.2.3 The Game behavior between high cost of developers and low cost of immigrants in the hydroelectric development project

When $P>\left(R_{s}-R_{f}+f^{*} c_{2}+Q\right)$ and $c<\left(Q+f^{*} c_{1}\right)$, the replicated dynamic equation of Game model has four equilibrium points: $(0,0),(1,0),(1,1)$ and $(0,1)$. Table 4 illustrates the value and trace of matrix of equilibrium point.

Table 3: Stable point analysis between low cost of developers and high cost of immigrants.

\begin{tabular}{|c|c|c|c|c|}
\hline \multicolumn{2}{|c|}{ Equilibrium point } & Equation & \multirow{2}{*}{$\begin{array}{c}\text { Symbol } \\
<0\end{array}$} & \multirow{2}{*}{$\begin{array}{c}\begin{array}{c}\text { Local } \\
\text { stability }\end{array} \\
\begin{array}{c}\text { Saddle } \\
\text { point }\end{array}\end{array}$} \\
\hline$x=0, y=0$ & $\operatorname{det} J$ & $\left(R_{s}-R_{f}+f * c_{2}-P\right)\left(Q+f * c_{1}-c\right)$ & & \\
\hline & $\operatorname{tr} J$ & $\left(R_{s}-R_{f}+f^{*} c_{2}-P\right)+\left(Q+f * c_{1}-c\right)$ & & \\
\hline \multirow[t]{2}{*}{$x=1, y=0$} & $\operatorname{det} J$ & $3\left(R_{s}-R_{f}+f * c_{2}-P\right) *(P-c)$ & $>0$ & \multirow[t]{2}{*}{$\begin{array}{l}\text { Unstable } \\
\text { point }\end{array}$} \\
\hline & $\operatorname{tr} J$ & $3\left(R_{s}-R_{f}+f * c_{2}-P\right)+(P-c)$ & $>0$ & \\
\hline \multirow[t]{2}{*}{$x=1, y=1$} & $\operatorname{det} J$ & $3\left(R_{s}-R_{f}+f * c_{2}+Q-P\right) *(-P+c)$ & $<0$ & \multirow[t]{2}{*}{$\begin{array}{l}\text { Saddle } \\
\text { point }\end{array}$} \\
\hline & $\operatorname{tr} J$ & $3\left(R_{s}-R_{f}+f * c_{2}+Q-P\right)+(-P+c)$ & $<0$ & \\
\hline \multirow[t]{2}{*}{$x=0, y=1$} & $\operatorname{det} J$ & $-\left(R_{s}-R_{f}+f * c_{2}+Q-P\right)\left(Q+f * c_{1}-c\right)$ & $>0$ & \multirow[t]{2}{*}{ ESS } \\
\hline & $\operatorname{tr} J$ & $\left(R_{s}-R_{f}+f * c_{2}+Q-P\right)-\left(Q+f * c_{1}-c\right)$ & $<0$ & \\
\hline
\end{tabular}


Table 4: Stable point analysis between high cost of developers and low cost of immigrants.

\begin{tabular}{lcccc}
\hline Equilibrium point & Equation & Symbol & $\begin{array}{c}\text { Local } \\
\text { stability }\end{array}$ \\
\hline$x=0, y=0$ & $\operatorname{det} J$ & $\left(R_{s}-R_{f}+f * c_{2}-P\right)\left(Q+f * c_{1}-c\right)$ & $<0$ & $\begin{array}{c}\text { Saddle } \\
\text { point }\end{array}$ \\
& $\operatorname{tr} J$ & $\left(R_{s}-R_{f}+f * c_{2}-P\right)+\left(Q+f * c_{1}-c\right)$ & & \\
$x=1, y=0$ & $\operatorname{det} J$ & $3\left(R_{s}-R_{f}+f * c_{2}-P\right) *(P-c)$ & $<0$ & Saddle \\
& $\operatorname{tr} J$ & $3\left(R_{s}-R_{f}+f * c_{2}-P\right)+(P-c)$ & point \\
$x=1, y=1$ & $\operatorname{det} J$ & $3\left(R_{s}-R_{f}+f * c_{2}+Q-P\right) *(-P+c)$ & $>0$ & ESS \\
& $\operatorname{tr} J$ & $3\left(R_{s}-R_{f}+f * c_{2}+Q-P\right)+(-P+c)$ & $<0$ & \\
$x=0, y=1$ & $\operatorname{det} J$ & $-\left(R_{s}-R_{f}+f * c_{2}+Q-P\right)\left(Q+f * c_{1}-c\right)$ & $>0$ & Unstable \\
& $\operatorname{tr} J$ & $\left(R_{s}-R_{f}+f * c_{2}+Q-P\right)-\left(Q+f * c_{1}-c\right)$ & $>0$ & point \\
\hline
\end{tabular}

Table 4 shows assuming high cost of developers and low cost of immigrants in the hydroelectric development project, the stability point is $(1,1)$, which means that the case is high cost of project and low cost of relocation, the developers implement project and the immigrants also choose relocation. In practice, based on the assumption that the thirst for clean energy is strong and the energy is shortage, the hydroelectric development project will have a certain nature of public utility so that the government is willing to support them. Therefore, even though the developers face high cost, they also choose to implement the project.

3.2.4 The Game behavior of the respective low cost between hydroelectric developers and immigrants

When $P<\left(R_{s}-R_{f}+f * c_{2}+Q\right)$ and $c<\left(Q+f * c_{1}\right)$, the replicated dynamic equation of Game model has four equilibrium points: $(0,0),(1,0),(1,1)$ and $(0,1)$. Table 5 illustrates the value and trace of matrix of equilibrium point. We can see that there is no stable point between developers and immigrants in the hydroelectric development project. For example, when $P<c,\left(x_{0}, y_{0}\right)$ is the center point, in which we have $x_{0}=\left(Q+f * c_{1}-c\right) /\left(Q+f * c_{1}-P\right)$, $y_{0}=\left(P-R_{s}+R_{f}-f * c_{2}\right) / Q$, and the center point will converge to $(0,0)$ as described in Table 5. When $P$ is persistently smaller than $c$, meaning that the developers constantly cut down the compensation of immigrants in order to reduce the cost, at the same time the immigrants do move and also require developers to explain the scheme, which do not allow the project to work normally. Thus, the developers have to give up the project.

From the above analysis on the evolutionary game between hydroelectric developers and immigrants in the hydroelectric development project, we can see that the stable point or optimal strategy is the respective high cost between hydroelectric developers and immigrants, which can impel to finish the hydroelectric project. In practice, there are some other cases that may happen in the hydroelectric project. In the hydroelectric project, whether relocation is high cost or low cost, the immigrants should have obtained the corresponding compensation. With the overall improvement of living standards, rapid economic development and the 
Table 5: Stable point analysis of the respective low cost between developers and immigrants.

\begin{tabular}{|c|c|c|c|c|}
\hline \multicolumn{2}{|c|}{ Equilibrium point } & Equation & \multirow{2}{*}{$\begin{array}{c}\text { Symbol } \\
>0\end{array}$} & \multirow{3}{*}{$\begin{array}{c}\begin{array}{c}\text { Local } \\
\text { stability }\end{array} \\
\begin{array}{c}\text { Unstable } \\
\text { point }\end{array}\end{array}$} \\
\hline$x=0, y=0$ & $\operatorname{det} J$ & $\left(R_{s}-R_{f}+f * c_{2}-P\right)\left(Q+f * c_{1}-c\right)$ & & \\
\hline & $\operatorname{tr} J$ & $\left(R_{s}-R_{f}+f^{*} c_{2}-P\right)+\left(Q+f * c_{1}-c\right)$ & $>0$ & \\
\hline \multirow[t]{2}{*}{$x=1, y=0$} & $\operatorname{det} J$ & $3\left(R_{s}-R_{f}+f * c_{2}-P\right) *(P-c)$ & $>0$ & \multirow{2}{*}{$\begin{array}{l}\text { Unstable } \\
\text { point }\end{array}$} \\
\hline & $\operatorname{tr} J$ & $3\left(R_{s}-R_{f}+f * c_{2}-P\right)+(P-c)$ & $>0$ & \\
\hline \multirow[t]{2}{*}{$x=1, y=1$} & $\operatorname{det} J$ & $3\left(R_{s}-R_{f}+f * c_{2}+Q-P\right) *(-P+c)$ & $<0$ & \multirow[t]{2}{*}{$\begin{array}{l}\text { Saddle } \\
\text { point }\end{array}$} \\
\hline & $\operatorname{tr} J$ & $3\left(R_{s}-R_{f}+f * c_{2}+Q-P\right)+(-P+c)$ & & \\
\hline \multirow[t]{2}{*}{$x=0, y=1$} & $\operatorname{det} J$ & $-\left(R_{s}-R_{f}+f * c_{2}+Q-P\right)\left(Q+f * c_{1}-c\right)$ & $<0$ & \multirow[t]{2}{*}{$\begin{array}{l}\text { Saddle } \\
\text { point }\end{array}$} \\
\hline & $\operatorname{tr} J$ & $\left(R_{s}-R_{f}+f * c_{2}+Q-P\right)-\left(Q+f * c_{1}-c\right)$ & & \\
\hline \multirow[t]{2}{*}{$x=x_{0}, y=y_{0}$} & $\operatorname{det} J$ & {$\left[x_{0}\left(1+x_{0}\right) Q\right]\left[y_{0}\left(1-y_{0}\right)\left(Q-P+f * c_{1}\right)\right]$} & $>0$ & \multirow[t]{2}{*}{$\begin{array}{l}\text { Center } \\
\text { point }\end{array}$} \\
\hline & $\operatorname{tr} J$ & 0 & & \\
\hline
\end{tabular}

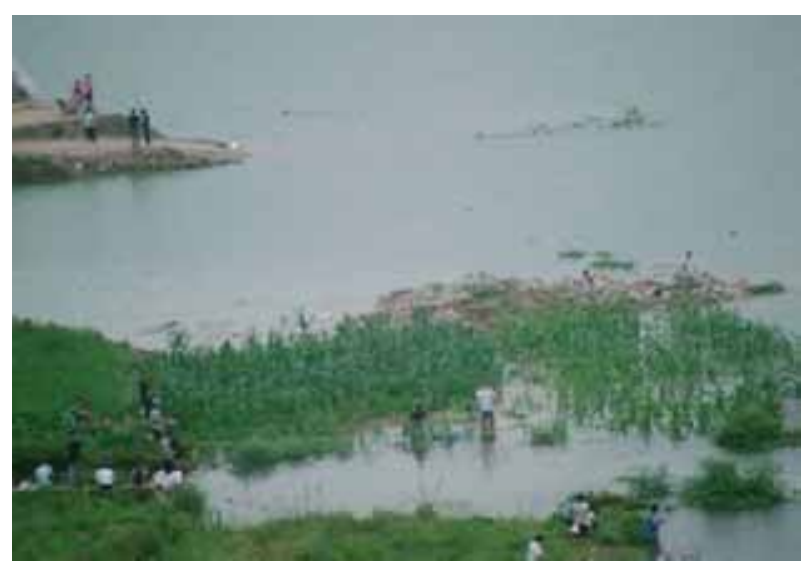

Figure 1: The situation of water storage in Hanyuan.

enhancement of people's self-awareness of rights and so on, it is indisputable truth that the cost of relocation is increasingly high in the current hydroelectric development project. To avoid the event like Hanyuan, the compensation not only should contain the resettlement of building but also should cover the survival and development of immigrants in the future. It was the construction of hydropower station in Hanyuan, flooded farmland and housing that caused resentment among local residents and the emergence of mass demonstrations.

The Dadu River Pubugou Hydropower Station built in Hanyuan was completed and put into use in the end of 2010, which covered a lot of farmlands for its completion (such as in Fig. 1). 


\subsection{The substitution effect of the hydroelectric power}

If we take the Dadu River Valley as an example, the annual developing amount calculated at 98.578 billion kilowatt per hour is equal to 12.115 million tons of standard coal, which can release gases, such as 30.2027 million tons of $\mathrm{CO}_{2}, 330,700$ tons of $\mathrm{SO}_{2}$, into the atmosphere after it is burned. It can replace 8.4803 million tons of fuel oil and 772.5 million cubic meters of natural gas. The Dadu River hydropower resources can reduce emissions to the atmosphere. (The standard of conversion can see the statistical yearbook of China.)

\section{COUNTERMEASURES AND SUGGESTIONS}

Hydropower is a renewable clean energy. The vigorous development of hydropower resources not only can ease the energy shortage but also help reduce carbon emissions.

In this paper, we establish a game payoff matrix between immigrations and the developers of the project of the hydropower development. By analyzing the accommodation and stability of the two variables, we draw the conclusion that: if we want to achieve the success of the project, both the immigration and the developers should pay high prices. People are willing to accept the high cost of immigration since it is likely to gain more compensation than the cost during the relocation $(P>C)$ and the achievements of the rapid developing of the external economy induce people to move out in spite of the high cost.

Faced with the high cost of relocation, the developers have no choice but accept the reality. It is also due to this reason, the hydropower project develops slowly. Thus, we put forward the following suggestions:

First of all, improve the compensation policy for settlers and realize the harmonious development between the project and the society. The success of the project depends on whether the residents are willing to move out, which related to the compensation policy. Improving the compensation policy for settlers is the key point both to the successful of the project and to the achievement of the harmonious society. In particular, developing a dynamic protection system for immigrations and carrying out a 'long-term compensation, later-period assistance' policy are two possibilities to improve the compensation policy. Moreover, in order to avoid group events, we should convert the involuntary immigrants to voluntary immigrants.

Secondly, the government should broaden the financing channels and strengthen the support. According to the principles of 'It is the one who benefits from the project must compensate for the settlers', the developers should not only pay for the capital of development but also pay for the compensation. Moreover, the project of the hydropower development is also a kind of public utility. For that reason, the government should support the project both in the respects of policy and capital. The government should take some measures to broaden the financing channels of hydropower developers such as cutting tax, issuing bonds, and providing low-interest loans.

Thirdly, we ought to strengthen the management and promote the orderly development in the project of hydropower development. Hydropower is a renewable energy, which has the advantages such as a low cost in power generation and flexibility in transmission. Our country is rich in water resources and has great potential for hydropower development. In order to avoid disorderly development and the problems related to ecological environment, immigrants and interest disputes, we should strengthen the management as well as the developing of hydropower.

In this paper, we only consider the relationship between the developer and the immigrants. In fact, the factors such as governments, institutions and ecological environment also have an impact on the project of hydropower development. These need further study. 


\section{ACKNOWLEDGEMENT}

This paper is the phase achievement research of National Social Science Fund Projects (11BJY058) and Chongqing Technology and Business University Doctor Foundation (670100206).

\section{REFERENCES}

[1] Sala, S. \& Castellani, V., Technology sustainability assessment to support decision making on energy production at local scale. International Journal of Sustainable Development and Planning, 6(3), pp. 251-267, 2011. doi: http://dx.doi.org/10.2495/SDP-V6N3-251-267

[2] A. Boeri \& Longo., D., Energy efficiency in buildings in Southern Europe: challenges and design strategies. International Journal of Sustainable Development and Planning, 6(4), pp. 522-536, 2011. doi: http://dx.doi.org/10.2495/SDP-V6-N4-522-536

[3] Raul Gouvea. Brazil's energy divide: sustainable energy alternatives for the Brazilian Amazon Region. International Journal of Sustainable Development and Planning, 7(4), pp. 472-483, 2012. doi: http://dx.doi.org/10.2495/SDP-V7-N4-472-483

[4] Shi Zuliu \& Sun Jinhua, Game analysis of three parties behavior in the hydraulic engineering resettlement management. Yellow River, 25(2), pp. 44-45, 2003.

[5] Fan Hui \& Liu Yufeng, The leap forward of hydropower generate interest game. China Newsweek, 46, pp. 44-47, 2004.

[6] Su Qian, The interest group of game of decision in the hydroelectric project. Nei Jiang ke ji, (7), pp. 110-110, 2006.

[7] Zeng Jiansheng, An necessary analysis of management for industry of implementation reservoir resettlement based on the tripartite game relationship. Water Resources Planning and Design, (3), pp. 4-7, 2008.

[8] Li Qinghua, The game of hydropower interests and the legal regulation about development and utilization. Theory and Contemporary, (10), pp. 23-25, 2009.

[9] Yan Dengcai Shi Guoqing \& Yi Qingshan, Hydropower development and minority resettlement development - take Yantan reservoir area for example. Guangxi Ethnic Studies, (2), pp. 162-167, 2012.

[10] Liu Jianhua, Social cooperation and interests coordination: a review of foreign public goods game experiment. West Forum, 23(1), pp. 59-69, 2013.

[11] Jin Jingyu, Tan Deqing \& Cai Jirong, An analysis of city alliances in the light of evolutionary game theory based on benefit distribution. Soft Science, 26(6), pp. 38-42, 2012.

[12] Wu Xiangyou \& Zhang Wei, Game analysis of evolution of agricultural insurance participation rate. West Forum, 20(1), pp. 68-73, 2010. 